\title{
Assessment of membrane plants for biogas upgrading to biomethane at zero methane emission
}

\author{
Gianluca Valenti ${ }^{1,}$, Alessandro Arcidiacono ${ }^{1}$, José Antonio Nieto Ruiz ${ }^{2}$ \\ ${ }^{1}$ Politecnico di Milano, Dipartimento di Energia, Via Lambruschini 4A, 20156 Milano (ITALY) \\ 2 Universidad Politécnica de Madrid, Calle Ramiro de Maeztu, 7, 28040 Madrid (SPAIN)
}

\section{Abstract}

In the future energy infrastructure there is a considerable potential for biogas and, in particular, for biomethane as a natural gas substitute. Among the alternatives of upgrading biogas to biomethane, this work focuses on membrane permeation. Taking cellulose acetate as membrane material and spiral-wound as membrane configuration, five layouts are assessed. All layouts have the same biogas plant rated at $500 \mathrm{~m}^{3} / \mathrm{h}$ (STP), yet they may adopt: (i) one- or two-stage permeation, (ii) permeate or residue recycle, and (iii) a water heater or a prime mover (internal combustion engine or a micro gas turbine) to exploit residues as fuel gas. Since residues are consumed, all layouts have zero emission of methane into the atmosphere. The membrane material is modeled considering the phenomenon of plasticization; the membrane modules are described by a crossflow permeation patterns without pressure drops. The results indicates that specific membrane areas range from 1.1 to $2.4 \mathrm{~m}^{2} \mathrm{~h} / \mathrm{m}^{3}$ (STP), specific energy from 0.33 to $0.47 \mathrm{kWh} / \mathrm{m}^{3}$ (STP), and exergy efficiencies from $57.6 \%$ to $88.9 \%$. The splitting of permeation over two stages and the adoption of water heater instead of prime movers is a convenient option. The preferred layout employs a single compressor, a two-stage membrane permeation at 26 bar, a water heater fueled by the first-stage permeate, and a second-stage permeate recycle. Assuming a biomethane incentive of $80 € / M W h_{L H V}$ and a project life of 15 years, the total investment of this plant is $2.9 \mathrm{M} €$, the payback time 5 years and the net present value $3.5 \mathrm{M} €$.

Keywords: biomethane; biogas upgrading; membrane; natural gas substitute; process simulation.

${ }^{*}$ Corresponding author. Phone: +39-02-2399.3845. Email: gianluca.valenti@polimi.it. Web: www.gecos.polimi.it 
 \\ 1 Introduction}

The future energy infrastructure will be based likely and largely on renewable sources. In this scenario, there is a considerable potential for biogas production from anaerobic digestion of agricultural byproducts, animal manure and slurry. Holm et al. [1] estimate that at least $25 \%$ of the whole bioenergy produced in Europe can originate from the digestion of wet biological materials.

The composition of a biogas depends strongly on the organic substrate and the digestion conditions. Typically, biogas has two main constituents, methane and carbon dioxide, and other minor components, water, hydrogen sulfide, nitrogen and oxygen, as well as ammonia and other organic components in very low quantities. The bulk presence of carbon dioxide reduces significantly the calorific value of the gas, whereas the minor components may lead to critical operational problems, like corrosion and clogging. Thus, biogas upgrading to a higher quality combustible gas, the so-called biomethane, requires removing most of that carbon dioxide and of the minor components. Their removal may be achieved by a variety of processes. Ryckebosch et al. [2] provide an accurate review of a large number of these processes, including the membrane systems that are the focus of this assessment. According to the review, the main advantages of the membrane technology are simple construction, easy operation and high reliability, while the general disadvantages are a low selectivity and the possibility of requiring multiple stages.

Technologies for the carbon dioxide separation differ by physical principle, plant layout, removal effectiveness, energy requirements, investment costs, operational efforts as well as the amount of methane that may be unrecovered. Among these technologies, membranes are recognized to be simple, reliable and modular. However, they may require multiple stages to achieve high purities at low methane losses, they cannot recover completely the methane, and they have not found yet a large market diffusion. Nevertheless, market share will predictably increase as membrane materials are improving.

The present paper focuses specifically on agricultural biogas due to the larger potential of this substrate compared to others. Agricultural biogas plants are usually small, located in rural areas, and operated by 
very few technicians. ${ }^{\dagger}$ In this rural context, the biogas upgrading process must be simple and reliable.

Naturally, the membrane technology is chosen for the scope. Among all possible materials and modules, cellulose acetate spiral-wound membranes are selected because, despite they are not the best performing option, they are common and robust, as demonstrated by UOP Separex ${ }^{\mathrm{TM}}$ and former Grace Membrane Systems technologies [3, Table 2], meeting the mentioned requirement of simplicity and reliability set for the installation in the agricultural sites.

Five layouts of the membrane plant, alternatively connected to the same biogas plant, are assessed here from energy, economic and exergy perspectives. All plants produce pipeline-quality biomethane, inject it into a mid-pressure (5-10 bar) natural gas pipeline, and avoid emitting methane into the atmosphere. The plants differ by:

- number of membrane stages (one or two),

- presence and type of recycles (permeate or residue),

- type of system utilizing the residue gas as fuel gas to avoid the methane emission (internal combustion engine, micro turbine and heater).

All layouts are first optimized economically, as a function of the operational parameters, and then compared against each other. The objective is to determine the strategic layout with the best overall performances. The exergy analysis is employed to identify the major sources of thermodynamic losses.

Methodologically, all layouts are modeled with a bottom-up approach through three levels:

- membrane material (here cellulose acetate as said),

- membrane module (spiral-wound),

- membrane process (five alternative layouts).

The models of membrane plants include all the necessary operational units (compressors, air coolers, and fuel gas utilizers) that constitute the upgrading process. The biogas plant is instead defined in an

\footnotetext{
${ }^{\dagger}$ Here biogas plant refers to the system that converts wet biomass into dehumidified and desulfurized biogas, which could be used in internal combustion engines, while membrane plant to the system that upgrades that biogas into biomethane by membrane technology.
} 
approximate manner because of its minor interest from the overall process perspective. All models are implemented in a Matlab code developed for the purpose.

To the best knowledge of the authors, the novelty of this paper resides first in the types of considered layouts, which may employ a micro gas turbines as opposed to the commonly considered internal combustion engines or which may combine multiple membrane stages with a heater. Moreover, the biogas plant and the membrane plant are simulated altogether, while most of the studies focus only on the latter. Finally, the simulations do not consider only mass and energy balances, but also an economic assessment over the entire plant lifetime and an exergy evaluation, both of which are original.

The following sections provide in sequence: a general bibliographic review on membrane materials, modules and processes; a description of the considered plants as well as of the numerical models; the numerical results along with their discussion and, ultimately, the conclusions and the future developments.

\section{Bibliographic review}

The next paragraphs review those studies that provide an overview on the topic or that focus on the three scales of the problem: materials, modules and process. For completeness, the sections include cellulose acetate and polyimide as well as spiral-wound and hollow-fiber membranes, despite this assessment covers solely cellulose acetate spiral-wound membranes.

\subsection{Overview}

Baker [4] describes the membranes from the lower scale of solution-diffusion mechanism to the larger scale of commercial plants. Membrane modules for carbon dioxide removal from methane-rich streams are technically viable. They turn economically competitive for flow rates smaller than $3,500 \mathrm{~m}^{3} / \mathrm{h}$ at the Standard Temperature and Pressure (STP) conditions of $0^{\circ} \mathrm{C}$ and 1 bar. This statement is in agreement with the plant size adopted in this work of $500 \mathrm{~m}^{3} / \mathrm{h}$ (STP), as outlined in Section 3 .

A review of biogas upgrading by membrane technology is provided by Scholz et al. [5]. According to the authors, available materials are suitable for harsh working conditions of high pressure (around 25 bar) and 
of chemically aggressive components $\left(\mathrm{H}_{2} \mathrm{~S}\right.$, in particular when $\mathrm{H}_{2} \mathrm{O}$ is also present). Single-stage permeation processes are not able to simultaneously produce a high $\mathrm{CH}_{4}$ purity and obtain a high $\mathrm{CH}_{4}$ recovery. Hence, multistage layouts become mandatory. Both Baker [4] and Scholz et al. [5] highlight the need for utilizing or even flaring the permeate gas. Sharing this observation, the present work considers only layouts that utilize entirely the permeate.

\subsection{Materials}

There are many materials proposed for biogas upgrading. According to Basu et al. [6], the most common for commercial applications are polymeric materials, in particular cellulose acetate and polyimide.

Harasimowicz et al. [7] report that the high permeability of the polyimide membranes to $\mathrm{H}_{2} \mathrm{O}$ and $\mathrm{H}_{2} \mathrm{~S}$ makes them useful for biogas processing without special pre-treatment, while cellulose acetate membranes, which are sensitive to water vapor, require water removal. The biogas upgrading layouts considered here comprise both $\mathrm{H}_{2} \mathrm{O}$ and $\mathrm{H}_{2} \mathrm{~S}$ abatements.

A problem of polymeric membrane is plasticization, which is the sorption of $\mathrm{CO}_{2}$ in the polymer matrix that causes a higher polymer chain mobility and, ultimately, a higher mass transport of all gases. Lee et al. [8] describe the effect of plasticization in cellulose acetate membranes by a modified dual-mode theory with concentration-dependent diffusivities, whereas Kanehashi et al. [9] illustrate the plasticization in a polyimide membrane. Both these materials show an appreciable plasticization at pressures above the threshold of $10 \mathrm{~atm}$, which can be raised to $30 \mathrm{~atm}$ by special material treatment. The work of Lee et al. [8] is taken as reference for the material modeling (Section 4.1).

\subsection{Modules}

Commercial membranes for gas separation applications are usually spiral-wound or hollow-fiber modules.

The later modules can be designed in coflow, counterflow and crossflow arrangement, while the former in crossflow. Their mathematical models can be solved analytically for simplified cases or numerically for general applications. The analytical solution for crossflow gas permeation of binary mixtures under simplifying condition is presented first by Weller and Steiner in 1950 [10], and extended by Stern and 
Walavender in 1969 [11], who also correct the membrane area calculation for the crossflow case. These

121 analytical solutions are used here to verify the correct model implementation under simplifying

122 assumptions, as noted in Section 4.2.

123 A simple yet robust numerical solution for multicomponent crossflow systems is outlined by

124 Kohl and Nielsen [12, Ch. 15]. This solution considers small incremental areas of the membrane (namely,

125 succession of stages): a permeation analysis and a material balance are performed on the first incremental

126 area, the residue gas from this area is treated then as the feed to the next area and the operation is

127 repeated iteratively. Thundyl and Koros [13], Tessendorf et al. [14], as well as Makaruk and Harasek [15]

128 present optimal algorithms for multicomponent gas separation in coflow, counterflow and crossflow

129 configurations, proving that crossflow is more effective than coflow always and than counterflow in some

130 cases. Despite the simplicity, the approach by Kohl and Nielsen [12, Ch. 15] is adapt for this study.

\section{$131 \quad 2.4 \quad$ Processes}

132 Membrane plants for natural gas and biogas upgrading share the feature of separating carbon dioxide from 133 a methane-rich stream. Hao et al. $[16,17]$ describe technically and economically polyimide membranes for 134 both $\mathrm{CO}_{2}$ and $\mathrm{H}_{2} \mathrm{~S}$ separation in single- and multi-stage layouts with various recycle options.

135 Qi and Henson [18] describe different layouts based on spiral-wound modules for natural gas treatment 136 and enhanced oil recovery. The most promising schemes by Hao et al. [16,17] and Qi and Henson [18] are 137 taken as reference in this assessment.

138 Makaruk et al. [19] investigate diverse membrane systems for biomethane production, including single- and 139 double-stage arrangements. The authors state that single-stage and double-stage cascade with permeate 140 recycle provide good flexibility for the integration with biogas plants and that the specific electric 141 consumption for biogas upgrading is about $0.3 \mathrm{kWh} / \mathrm{m}^{3}$ (STP). In addition, they propose the use of the 142 permeate gas as a fuel for either an internal combustion engine, in single-stage layouts, or a 143 porous/catalytic burner, in double-stage layouts. 
Finally, Deng and Hägg [20] study an efficient $\mathrm{CO}_{2}$-selective polyvinylamine/polyvinylalcohol (PVAm/PVA) blend membrane by conducting an experimental analysis of the material and, then, a numerical simulation of a whole plant. They consider a farm-scale system rated at $1000 \mathrm{~m}^{3} / \mathrm{h}$ (STP) and four layouts. The doublestage cascade layout with residue recycle is proven optimal among the four processes with an area, expressed in specific terms with respect to the produced biomethane, of $1.69 \mathrm{~m}^{2} \mathrm{~h} / \mathrm{m}^{3}$ (STP) and a specific electric consumption of $0.29 \mathrm{kWh} / \mathrm{m}^{3}$ (STP) [20, Table 6 - case c]. The investment of the optimal membrane plant is 3.06 M\$. The energy and economic results by Makaruk et al. [19] and by Deng and Hägg [20] are taken as reference for the present work (Section 5.3).

\section{Plant description}

The present work assumes a biogas plant rated at $500 \mathrm{~m}^{3} / \mathrm{h}$ (STP). The raw biogas is treated to separate water by condensation and adsorption on silica and hydrogen sulfide by adsorption on "iron sponges" prior to entering the membrane plant. The adsorption cartridges are replaced periodically and regenerated externally from the plant. The biogas plant is connected to a membrane plant, which may have five alternative layouts. Membrane material is cellulose acetate, while module is spiral-wound. The five plant layouts include single- and double-stage arrangements, residue and permeate recycles, and diverse residue utilizations as fuel gas as describe in the following sections.

\subsection{Biogas plant}

The biogas plant has three main electrical power consumptions for: (i) the biomass handling and conveying to the digester, (ii) the mixing of the biomass within the digester and (iii) the drying of the biogas prior to entering the membrane plant. In addition, it has a thermal power utilization to keep the digesters at the optimal temperature $\left(35\right.$ to $\left.55^{\circ} \mathrm{C}\right)$. Electrical and thermal power requirements are treated as lumped sums.

\subsection{Membrane plants: the five layouts}

The membrane plants differ by type, number and arrangement of the operational units. They may employ a diverse number of air-cooled oil-free reciprocating compressors (indicated by the acronym CMP). They may 
have one or two membrane stages (MBR). Membranes operate at a pressure higher than the 5-10 bar grid assumed here, so that biomethane is throttled into the pipeline. Because it is not possible to recover the whole of the methane, all membrane layouts adopt a way to utilize the permeate as a fuel gas in a combustion process. This way may be an internal combustion engine (ICE), a micro gas turbine (MGT), or simply a conventional water heater (HTR). Engine, turbine and heater work at the minimum methane fraction in the fuel gas allowed by the technology. Moreover, internal combustion engines and micro gas turbines produce electrical power that is partly consumed on-site and partly exported to grid, and thermal power that is partly consumed on-site and partly dissipated into the ambient. The conventional water heater produces thermal power that is consumed on-site and partly dissipated when in excess. The five layouts are as follows.

Layout 1 Single-stage permeation and internal combustion engine (Figure 1).

Layout 2 Single-stage permeation and micro gas turbine (Figure 2).

Layout 3 Double-stage permeation with second-stage permeate recycle, single-stage compression and heater (Figure 3).

Layout 4 Double-stage permeation with second-stage residue recycle, first-stage permeate recompression and heater (Figure 4).

Layout 5 Double-stage permeation with second-stage permeate recycle, two-stage compression and micro gas turbine (Figure 5).

Layout 1 and Layout 2 are the basic membrane layouts in which the permeate is used as a fuel gas in a power cycle. Layout 1 adopts an internal combustion engine as power cycle because it is the most common technology in the biogas sector. In contrast, Layout 2 adopts a micro gas turbine that can work on a poorer fuel gas (lower methane content) because it utilizes a dedicated component, the combustor, to burn the gas. As a positive consequence, Layout 2 allows for a higher biomethane production. However, the micro 
gas turbine requires a compressor to increase the pressure of the fuel gas. ${ }^{\ddagger}$ In both layouts a biogas bypass

192 is necessary to increase the methane content in the permeate.

193 Layout 3 is an evolution of the previous two layouts in which the fuel gas utilizer is a water heater that can 194 work on an even poorer gas than the micro gas turbine. Given typical values of membrane selectivity, it is 195 impossible to achieve a very high methane content in the residue and, simultaneously, a low content in the permeate. Therefore, a second stage of permeation is needed. In Layout 3, this second stage processes the residue from the first stage in order to produce the biomethane for the grid. In its turn, the permeate from the second stage, which has a high methane content, is recycled back to the compressor.

Layout 4 is an alternative to Layout 3 in which the second stage of permeation processes the permeate (not the residue) from the first stage in order to produce the fuel gas for the heater (not the biomethane for the grid). A second compressor is required for increasing the permeate pressure to the same level as the first compressor (in other words, the two compressors have the same discharge pressure). In its turn, the residue from the second stage is recycled back to the first membrane.

Finally, Layout 5 is an evolution of Layout 2, inspired by Layout 3, in which there are two permeation stages working at two different pressure levels. The second permeation stage processes the residue from the first stage (similarly to Layout 3), but it operates at a higher pressure (contrarily to Layout 3). Compared to the compressor of Layout 2, the compressors of Layout 5 work at lower pressure ratios and flow rates. The permeate from the second stage is recycled to the first compressor (similarly to Layout 3).

\section{Plant simulations}

The mathematical model developed for the analysis of the membrane plants is based on the following general assumptions:

- water and hydrogen sulfide are not considered because separated prior to the membrane plant,

\footnotetext{
${ }^{\ddagger}$ In general, packaged micro gas turbines working on natural gas from the grid are equipped with a gas compressor; nevertheless, it is preferred here to keep the compressor separated from the package because the flow rate of the fuel gas is higher than the natural gas case given that the methane content is lower.
} 
- biogas consists exclusively in methane and carbon dioxide,

- both gases behaves as ideal gases,

- their heat capacities at constant pressure in the ideal gas stated are described via the Shomate equation with coefficients derived from the NIST Webbook [21],

Concerning thermodynamic properties, specific enthalpy, entropy and exergy of any $\mathrm{CO}_{2}-\mathrm{CH}_{4}$ mixture at any state derive from the proper integration of the equation of the heat capacity. Reference conditions are of 227 minor importance for energy, entropy and (physical) exergy balances because the flows are non-reactive. 228 Only the reference chemical exergy of methane is important for the exergy assessment.

\section{$229 \quad 4.1 \quad$ Material}

230 The expression of the permeance of $\mathrm{CO}_{2}$ (component 1 ) and of $\mathrm{CH}_{4}$ (component 2) through the material as 231 a function of their partial pressures in presence of plasticization is taken from Lee et al. [8]. The permeance 232 of $\mathrm{CO}_{2}, P_{1}$, turns to be:

$$
P_{1}=\frac{D_{1}^{\circ} / \delta}{\left(\beta_{1}+\beta_{2} B\right)\left(p_{h_{1}}-p_{l_{1}}\right)}\left\{\exp \left[\left(\beta_{1}+\beta_{2} B\right)\left(k_{D_{1}} p_{1}+\frac{C_{H}^{\prime} b_{1} p_{1}}{1+b_{1} p_{1}+b_{2} p_{2}}\right)\right]\right\}_{p_{l}}^{p_{h}}
$$

233 while the permeance of $\mathrm{CH}_{4}, P_{2}$ : 


$$
P_{2}=\frac{D_{2}^{\circ} / \delta}{\left(\frac{\beta_{1}}{B}+\beta_{2}\right)\left(p_{h_{2}}-p_{l_{2}}\right)}\left\{\exp \left[\left(\frac{\beta_{1}}{B}+\beta_{2}\right)\left(k_{D_{2}} p_{2}+\frac{C_{H}^{\prime} b_{2} p_{2}}{1+b_{1} p_{1}+b_{2} p_{2}}\right)\right]\right\}_{p_{l}}^{p_{h}}
$$

234 where $\delta$ is the membrane thickness, $D_{i}^{\circ}$ is the effective diffusivity of the $i$-th component at infinitely dilute 235 concentration, $\beta_{i}$ a parameter related to the effective diffusivity to be determined by nonlinear regression, $k_{D_{i}}$ the dissolution coefficient, $C_{H}^{\prime}$ the saturated concentration of adsorbed gas, $b_{i}$ the adsorption equilibrium constant, $p_{h_{i}}$ and $p_{l_{i}}$ the partial pressures in the high pressure side and in the low pressure side respectively. The braces contain the difference of the exponentials evaluated at the high- and the lowpressure sides. Lastly, the parameter $B$ is:

$$
B=\frac{k_{D_{2}} p_{h_{2}}\left(1+b_{1} p_{h_{1}}+b_{2} p_{h_{2}}\right)+C_{H}^{\prime} b_{2} p_{h_{2}}}{k_{D_{1}} p_{h_{1}}\left(1+b_{1} p_{h_{1}}+b_{2} p_{h_{2}}\right)+C_{H}^{\prime} b_{1} p_{h_{1}}}
$$

\subsection{Module}

The spiral-wound modules adopted in this work are modeled as crossflow systems. The analytical solution proposed by Weller and Steiner [10], later corrected by Stern and Walawender [11], cannot be employed because the permeance of the components are not constant, but affected by the concentration through the plasticization equations 1 and $2 .{ }^{\S}$ The simple and robust iterative approach illustrated by Kohl and Nielsen [12] is simplified from the multicomponent case to this binary problem. According to their approach, a process simulation can be made by considering small incremental areas of the membrane. A permeation analysis and a material balance are performed on the first incremental area. The residue gas from this area is treated as the feed to the next area, and the operation is repeated sequentially.

For the $k$-th incremental area, the composition of the permeate side, i.e. the low-pressure side, for a binary mixture in a crossflow membrane can be expressed as [4]:

\footnotetext{
${ }^{\S}$ The analytical model is utilized anyhow to validate the numerical model imposing constant values for the component permeances.
} 


$$
x_{l_{i}}^{(k)}=\frac{\varphi}{2}\left[x_{h_{i}}^{(k)}+\frac{1}{\varphi}+\frac{1}{\alpha^{(k)}-1}-\sqrt{\left(x_{h_{i}}^{(k)}+\frac{1}{\varphi}+\frac{1}{\alpha^{(k)}-1}\right)^{2}-\frac{4 \alpha^{(k)} x_{h_{i}}^{(k)}}{\left(\alpha^{(k)}-1\right) \varphi}}\right]
$$

251 where $x_{h_{i}}^{(k)}$ and $x_{l_{i}}^{(k)}$ are the $i$-th component feed and permeate compositions respectively, $\alpha^{(k)}$ the 252 selectivity $\left(P_{1} / P_{2}\right)$, and $\varphi$ is the pressure ratio $\left(p_{h} / p_{l}\right)$, which is the only parameter independent from $k$.

253 For the particular case of crossflow pattern, $x_{l_{i}}^{(k)}$ is only dependent on $x_{h_{i}}^{(k)}$ and $\varphi$, but not on $x_{l_{i}}^{(k-1)}$.

254 Because the calculation of permeances is a function of $\mathrm{CO}_{2}$ and $\mathrm{CH}_{4}$ partial pressures at each $k$-th 255 incremental area, the resulting set of equations at any incremental area comprises the three implicit 256 equations 1, 2 and 4 . The set of equations must be solved iteratively by direct substitution at each 257 incremental area in sequence. Once the $k-1$ incremental area is solved, the high-pressure composition of 258 the $k$-th area is known (thanks to equation 8 reported below). Next, the permeances of $k$-th area are taken 259 equal to those of $k-1$ area as a first guest. At this point the iterative procedure starts: the low-pressure composition is computed according to equation 4 and the new permeances according to equation 1 and 2 . These new values of permeances are substituted over the previous values iteratively until the maximum variation among new and old values is below a desired tolerance. incremental area is (see Figure 6):

$$
M_{i}^{(k)}=P_{i}^{(k)}\left(x_{h_{i}}^{(k)} p_{h}-x_{l_{i}}^{(k)} p_{l}\right) \Delta A
$$

265 where $M_{i}^{(k)}$ is the $i$-th component molar flow across the membrane and $\Delta A$ is the small incremental area, 266 chosen arbitrarily. The increase in permeate molar flow of the $i$-th component, $O_{i}^{(k+1)}$, at each $\Delta \mathrm{A}$ is:

$$
O_{i}^{(k+1)}=O_{i}^{(k)}+M_{i}^{(k)}
$$

267 whereas the corresponding decrease in residue molar flow, $N_{i}^{(k+1)}$, is: 


$$
N_{i}^{(k+1)}=N_{i}^{(k)}-M_{i}^{(k)}
$$

268 and the boundary conditions are as follows: $O_{i}^{(1)}$ is null and $N_{i}^{(1)}$ is equal to the $i$-th component molar flow 269 in the feed.

270 The residue molar composition is updated as:

$$
x_{h_{i}}^{(k+1)}=\frac{N_{i}^{(k+1)}}{\sum_{i} N_{i}^{(k+1)}}
$$

271 while the membrane area as:

$$
A^{(k+1)}=A^{(k)}+\Delta A
$$

The procedure is repeated until the desired residue molar composition is met. Each increment of area is accumulated so that total area required is known, as well as the gas compositions and flows in the residue and in the permeate. The smaller the taken value of incremental area, the more accurate the result.

\subsection{Process}

In a membrane plant at least three operational units are required in addition to the membrane modules: gas compressors, gas coolers, and utilizer of the permeate gas as a fuel gas. In this work, compressors and coolers are combined in electric air-cooled oil-free reciprocating packages; compressors are characterized by constant isentropic and electric efficiencies, while coolers by a constant electric consumption per unit of heat dissipated. Concerning the permeate utilizers, internal combustion engines, micro gas turbines and water heaters are modeled with constant electrical and thermal efficiencies. The three utilizers differ in the value of the efficiencies and, importantly, in the minimum methane content in the fuel gas.

Mass, energy and exergy balances of the single units and the overall plant are executed by way of Classical Thermodynamics. In particular, the exergy efficiency of whole plant is defined as the ratio of the exiting exergy flow (biomethane from the membrane plant and electricity if produced) and the entering exergy flow (biomass to the biogas plant and electricity if consumed). For simplicity, the exergy flow of the 
entering biomass is taken equal to the exergy flow of the biogas to the membrane plant. Electrical and thermal powers consumed within the biogas plant are treated as wasted.

Biogas upgrading plants are assessed economically by way of the conventional Net Present Value (NPV) analysis. It is assumed that the total investment is paid in full at the instant "present", which is the moment the plant goes into operation. Cash flows are transacted at the end of each operation year for the total duration of the project lifetime.

The total investment is the sum of the biogas plant and the membrane plant costs. The biogas plant cost is treated as a constant lumped sum. In contrast, the membrane plant cost is estimated from the total base equipment cost, which is the sum of the costs of the main operational units (membranes, compressors, coolers, and permeate utilizers), following the single-factor method of Perry's Handbook [22, Ch. 9]. The cost of each unit, but the membrane modules, is evaluated by the exponential method [22]; the membrane module cost is simply linear with the membrane area. Ultimately, the total base equipment cost is increased by the single factor to yield the membrane plant investment. This factor is referred to as Balance of Plant (BOP) and expressed as a percentage. ${ }^{* *}$

Cash flows comprise yearly incomes, expenditures and taxes, which are all assumed to be constant over the project lifetime. Incomes include the sale of biomethane. Electricity may be purchased or sold to the grid, depending on the plant layout, and thus may fall among expenditures or incomes. Yearly amounts of biomethane and electricity are computed via the capacity factor. Expenditures include also the cost of the biomass supplied to the biogas plant as well as the cost of the Operation and Maintenance (O\&M). In its turn, O\&M cost is the sum of the costs for all the operational units and the cost for the remainder of the plant. The latter O\&M cost is estimated as a fraction of the total investment. Taxes are computed as a fraction of the earnings, while earnings are simply the incomes subtracted by expenditures and by amortization. The amortization is calculated as the total investment divided by the project lifetime.

\footnotetext{
** For example, if the total base equipement cost for the membrane plant is $100 \mathrm{k} €$ and the BOP is $200 \%$, the membrane plant investment is $100 *(1+200 \%)=300 \mathrm{k€}$.
} 
Ultimately, the NPV of each plant is determined discounting the yearly cash flows to the instant "present"

311 by a weighted average cost of the capital.

\subsection{Assumed parameters}

Several parameters are employed in the simulations. The parameters for equations from 1 to 3 referring specifically to the adopted material, cellulose acetate, are listed in Table 1. All other parameters can be divided into two major groups: technical parameters (mostly on the left side of Table 2) and economical parameters (right side). The technical parameters include: the characteristics of the dried gas from the biogas plant to the membrane plant as well as the characteristics of the biomethane injected into the grid; technical specifications of compressors, coolers, internal combustion engines, micro gas turbines, heaters; and references for the energy and the exergy analyses. The economical parameters include: fixed costs, cash flow parameters, and NPV factors. In particular, the dried biogas composition adopted here is typical of the anaerobic digestion of a mixture containing mainly animal manure and partly energy crops.

\subsection{Free parameters and their optimization}

The free parameter for Layout 1 thru Layout 3 is the discharge pressure of the compressor. Similarly, the only free parameter for Layout 4 is the discharge pressure of the first compressor, as the second one has the same pressure level. Lastly, the free parameters of Layout 5 are the discharge pressures of both compressors as well as the carbon dioxide content in the permeate from the first permeation stage. The mentioned free parameters of each layout are optimized in order to maximize the NPV of that layout over its lifetime.

\section{Plant results and discussion}

Model and assumptions are benchmarked with respect to a conventional biogas plant, in which biogas itself is utilized totally in an internal combustion engine to produce electricity. The code is employed then to optimize the five layouts of the membrane plant in order to, as explained above, maximize the NPV of all layouts. The optimal results are reported in Table 3 and discussed below. Subsequently, a sensitivity 
analysis of the biomethane incentive, which is a fundamental parameter, is executed and, lastly, an insight into the exergy and economic analyses of the preferred layout is provided.

\subsection{Methodology benchmark}

The methodology is benchmarked by assessing a conventional biogas plant that exports only electricity produced via an internal combustion engine. In this case, the BOP is taken equal to $100 \%$, in contrast to the value reported in Table 2 for the membrane plant, because it is a consolidated technology. For this validation plant, the assessment returns that the engine is rated at $1094 \mathrm{~kW}_{\mathrm{e}}$, the thermal power exceeds by far the biogas plant requirement, the net electrical power to the grid is $994 \mathrm{~kW}_{\mathrm{e}}$ and the exergy efficiency $35.1 \%$. From the economical perspective, the total investment is about $4.0 \mathrm{M} €$, which is equivalent to a specific cost of $4024 € / \mathrm{kW}_{\mathrm{e}}$, the yearly cash flow is $730 \mathrm{k} €$, the payback time is about 8 years and the NPV about 2.2 M€. These values are in good agreement with the study by Walla et al. [23] and the current state of the art.

\subsection{Layout optimization}

The NPV is related linearly with the biomethane incentive through the amount of produced biomethane. For each layout, the amount of produced biomethane is given by the overall mass balance and, thus, it is independent from the compressor discharge pressure. Consequently, biomethane incentive and compressor discharge pressure influence independently the NPV. In other words, the NPV is a linear combination of two functions, one dependent on the incentive (income) and the other on pressure (total investment and expenditures). Therefore, the compressor discharge pressure at which the NPV is maximum is independent from the incentive, as demonstrated numerically below.

For Layout 1 to 4, Figure 7 shows the normalized NPV as a function of the pressure for three diverse incentives (80, 100 and $\left.120 € / M W h_{\llcorner H V}\right)$. Each incentive curve is normalized with respect to its maximum. As reasoned above, the optimal pressure is independent from the incentive value. The optimal pressures, ranging from 24 to 26 bar, are slightly higher than 20 bar determined by Deng and Hägg [20]. The difference is related to the fact that the economical optimization favors higher compressor ratios, and thus 
more expensive compressors, reducing on the other hand the membrane surface, and thus their investment and maintenance costs. For Layout 5, Figure 7 shows the normalized NPV as a function of the second compressor discharge pressure and the $\mathrm{CO}_{2}$ content in the permeate. The surface is drawn for a single incentive value $\left(80 € / M W h_{\llcorner H V}\right)$. The optimal pressure is 46 bar, which leads to a first compressor discharge pressure of 6.8 bar, while the optimal carbon dioxide content in the permeate from the first stage is $92 \%$. These optimal pressures are achievable via conventional compressors and bearable by common membranes. The only exception is the second stage of Layout 5, which is relatively high; however, this layout will not turn to be the preferred one, as reported below.

\subsection{Overall performances of the optimized layouts}

The prediction of membrane areas, compressor sizes, prime mover as well as water heater sizes, biomethane flow rates and electricity (produced or consumed) of the optimized layouts are included in Table 3. In specific terms with respect to the produced biomethane, membrane extensions are around 1.1-1.2 $\mathrm{m}^{2} \mathrm{~h} / \mathrm{m}^{3}$ (STP) for Layout 1 to 3, 1.4 for Layout 4 and 2.4 for Layout 5 . Layout 4 shows a modestly larger membrane extension than Layout 1 and 2 because its first membrane stage operates on a greater flow rate as it adopts a recycle instead of a bypass of the biogas. Moreover, it shows a larger extension than Layout 3 because its first stage must achieve directly grid-quality requirements, whereas Layout 3 employs two stages to do so. Layout 5 requires the greatest membrane area because its first stage operates at low pressure. All layouts, but Layout 5, show lower membrane extensions than those predicted by Deng and Hägg [20] in strict agreement with the fact that, as reasoned previously, the maximization of NPV favors larger compressors and smaller modules.

The specific separation energy of Table 3 includes only the work for the separation compressors, not the fuel gas compressor of the micro gas turbine, nor the air-cooler, nor the electricity production when present in order to make the results comparable with other studies. These three items (fuel gas compressor, air-coolers and electricity production) are though included in the economic calculations. All layouts, but Layout 4 , have a specific separation energy of $0.33-0.38 \mathrm{kWh} / \mathrm{m}^{3}(\mathrm{STP})$, which are slightly higher than the 0.29-0.30 value by Makaruk et al. [19] and by Deng and Hägg [20]. This result is again in 
strict agreement with the fact that the maximization of the NPV favors larger compressors and smaller modules. Secondarily, the lower compressor efficiency assumed here because biogas flow rate and, thus, compressor sizes are smaller in this work yielding higher specific energies. The specific separation energy for Layout 4 is $0.47 \mathrm{kWh} / \mathrm{m}^{3}$ that is the highest because the second-stage compressors processes the permeate, which is at low pressure.

Exergy efficiencies of all layouts are appreciable higher than that of the conventional biogas plant, equal to 35.1\% (see Section 5.1). The exergy efficiency follow closely the biomethane production. Layout 1 shows the lowest value of almost $58 \%$ with a biomethane production of $928 \mathrm{~kW}$ LHV, Layout 2 and 5 a value of about $67 \%$ with a production of $1556 \mathrm{~kW} \mathrm{LHV}_{\mathrm{LV}}$, and Layout 3 and 4 around $88 \%$ with a production of 2496 kWLHV. Layout 3 has a modestly lower electricity consumption than Layout 4, and thus a modestly higher exergy efficiency. The most interesting outcome of the exergy analysis is, anyhow, the indication of which processes generates the largest irreversibilities. As reported later in Section 5.5, the most irreversible processes, which shall be addressed if possible, are fuel gas combustion and electrical consumption. Interestingly, air-cooling turns to be more irreversible than biogas compressing and separating. because they do not employ prime movers, which are expensive technologies. All others exceed 4.0 M€. Total investments include the biogas plant cost of $2.5 \mathrm{M€}$. In other words, the membrane plant cost ranges from 0.4 to over 1.5 M€, which are values lower than those computed by Deng and Hägg [20] because of the much lower plant size and the lower single factor assumed in this work. Cash flows and, thus, payback times as well as NPVs are computed with a biomethane incentive value of $80 € / M W h_{L H V}$ (the sensitivity analysis on the incentive is illustrated below). Layouts employing a micro gas turbine ( 2 and 5 ) yield the lowest cash flows because of the lower electrical efficiency. Among the others, Layout 4 is intermediate because of its high specific separation energy, while Layout 1 and 3 allow for the highest cash flows due to the highest electricity production and highest biomethane production, respectively. Similarly to the total 
again, they do not employ prime movers. In essence, the economical optimization favors the layouts that do not employ prime movers because they are expensive technologies.

For completeness, Figure 8 illustrates the $\mathrm{CO}_{2} / \mathrm{CH}_{4}$ selectivity as well as the $\mathrm{CO}_{2}$ permeance for Layout 1 as a function of the membrane incremental area, which is expressed in specific terms with respect to the produced biomethane at STP conditions $\left(\mathrm{CH}_{4}\right.$ permeance is not depicted, but it may be derived). The specific membrane area for Layout 1 is $1.23 \mathrm{~m}^{2} \mathrm{~h} / \mathrm{m}^{3}$ (STP), as reported in Table 3. Along the membrane, the selectivity is around 29, in agreement with the data reported by Lee et al. [8], and shows a maximum of almost 31. The maximum exists due to the relative variations of the $\mathrm{CO}_{2}$ permeance and of the $\mathrm{CH}_{4}$ permeance. Both permeances decrease monotonically. At low incremental areas the permeance of $\mathrm{CO}_{2}$ diminishes more gently than that of $\mathrm{CH}_{4}$ due to the positive effect of a lowering plasticization of the material thanks to a lowering $\mathrm{CO}_{2}$ concentration in the residue. Thus, the selectivity increases. However, at higher incremental areas the plasticization reduction becomes marginal and the permeance of $\mathrm{CO}_{2}$ diminishes more steeply than that of $\mathrm{CH}_{4}$. Thus, the selectivity decreases. These results are in agreement with similar ones in the literature (for instance Baker [4] or Kohl and Nielsen [12]); they indicate that material plasticization has an appreciable effect over the selectivity and, thus, it shall be included in the material modeling.

\subsection{Sensitivity analysis of biomethane incentive}

The biomethane incentive is a crucial parameter for the economical analysis. It varies among countries worldwide. For completeness, a sensitivity analysis on the incentive is conducted in the wide range from 40 to $120 € / \mathrm{MWh}_{\llcorner\mathrm{HV}}$. Figure 9 shows the NPV as a function of the biomethane incentive for the five layouts and, in addition, for the conventional biogas plant. The NPV of the conventional plant is, of course, independent from the incentive and it is equal to about 2.2 M€. The curve for Layout 1 is the less steep, while those for Layout 2 and 5 are intermediate, and Layout 3 and 4 are the steepest. In fact, the higher the biomethane production the higher the curve slope. Below $70 € / \mathrm{MWh}_{\mathrm{LHV}}$ none of the layouts is competitive compared to the conventional biogas plant; in the rough range between 70 and $80 € / M W h_{\text {LHV }}$ only Layout 3 and 4 become more convenient than conventional; and above $85 € / M W h_{\llcorner H V}$ all are economically attractive. 
In particular, Layout 3 and 4 are favored over a wide range of the incentives thanks to a higher biomethane production and a lower initial cost (as mentioned, they do not employ prime movers). From an investment perspective, they are the safest operation, even in the case of incentives varying over time.

\subsection{Insight in the preferred plant}

Layout 3 turns to be the preferred layout from both technical and economical perspectives, as it is rather simple and cost effective. Figure 10 visualizes its exergy efficiency and exergy losses. As explained in Section 4.3, the biomass exergy flow entering the biogas plant is taken numerically equal to the biogas exergy flow entering the membrane plant. The exergy efficiency is $88.9 \%$, which is a high value because most of the methane content in the biogas is converted into the biomethane. The larger exergy losses are related to the permeate use in the water heater (5.4\%) to keep the digester warm and to the electrical consumption (3.5\%) in the biogas plant, because both thermal and electrical powers are considered as lost (Section 4.3). Losses due to the compressor and its air-cooler are appreciable ( $0.4 \%$ and $0.9 \%$ respectively), while losses due to permeation in the two membrane stages are lower ( $0.6 \%$ and $0.2 \%)$. Biogas mixing with the permeate from the second membrane is negligible. Therefore, the water heater consumption shall be reduced to the amount strictly required by the digester for improving the overall performance, for instance by adopting catalytic burners that can operate on very poor fuel gas and, hence, with lower flow rates than the layouts considered here.

The annualized cash flows for Layout 3 are depicted in Figure 11. They decrease over the years due to the effected of the weighted average cost of capital. The NPV for a given year is the cumulative sum of the cash flows up to that year. The NPV turns from negative to positive in the $5^{\text {th }}$ year and, by the end of project, exceeds the total investment cost. A payback time of 5 years may be considered an interesting yet not outstanding result because energy supply from renewable sources is an increasing market in many Countries. 


\section{Conclusions}

The present work assesses technologically, energetically, exergetically and economically, five layouts for biogas upgrading to biomethane via membrane technology. These layouts are optimized maximizing their Net Present Value (NPV).The work draws the conclusions as reported in the following.

- Membrane biogas separation via cellulose acetate spiral-wound modules is technologically a viable option for biomethane production.

- Layouts that employ two-stage permeation and utilize a water heater instead of a prime mover (internal combustion engine or micro gas turbine) allow for the maximum biomethane production. Considering cellulose acetate as membrane material and spiral-wound as module configuration, permeation is to be operated optimally at about 26 bar.

- The optimal values of membrane areas expressed in specific terms with respect to the produced biomethane range from 1.1 to $2.4 \mathrm{~m}^{2} \mathrm{~h} / \mathrm{m}^{3}$ (STP) and the optimal values of specific energy from 0.33 to $0.47 \mathrm{kWh} / \mathrm{m}^{3}$ (STP), depending on the layout.

- The maximization of the NPV appears to favor larger compressors and smaller modules with respect to other studies in the literature that optimize in general the energy consumption.

- Biogas upgrading represents an appreciable improvement from an exergy perspective: in general, the higher the biomethane production the higher the exergy efficiency. Exergy efficiencies are in the range $57.7 \%-88.9 \%$, compared to $35.1 \%$ of the conventional biogas plant.

- For membrane plants connected to a biogas plant producing $500 \mathrm{~m}^{3} / \mathrm{h}$ (STP), total investment span from 2.9 to $4.4 \mathrm{M} €$, of which $2.5 \mathrm{M} €$ are due to the biogas plant. Assuming a biomethane incentive of $80 € / \mathrm{MWh}_{\text {LHV }}$ and a project life of 15 years, payback times fall in the 5-9 year range while Net Present Values in 1.8-3.5 M€.

- The economic feasibility of biogas upgrading via membrane technology is strictly dependent on the biomethane incentive: below $70 € / M W_{L H V}$ none of the layouts is viable; up to $85 € / \mathrm{MWh}_{L \mathrm{LV}}$ only the layouts employing water heaters instead of prime movers are viable; above $85 € / \mathrm{MWh}_{\mathrm{LHV}}$ all layout are viable. 
- The preferred layout (Layout 3) employs a single compressor, a two-stage membrane permeation operating at about 26 bar and a permeate-fueled water heater: its plant simplicity and the prime mover exclusion are the winning factors.

488 The future work will focus on simulating hollow-fiber polyimide modules, which require pressure drop

489 models, and on investigating the use of catalytic heaters that can operate at low methane content.

\section{Acknowledgement}

491 The authors are very grateful to Mr. Luca Talia and Mr. Alberto Giannone from Sebigas S.p.a. for the fruitful 492 exchange of opinions.

\section{Nomenclature}

\section{Acronyms}

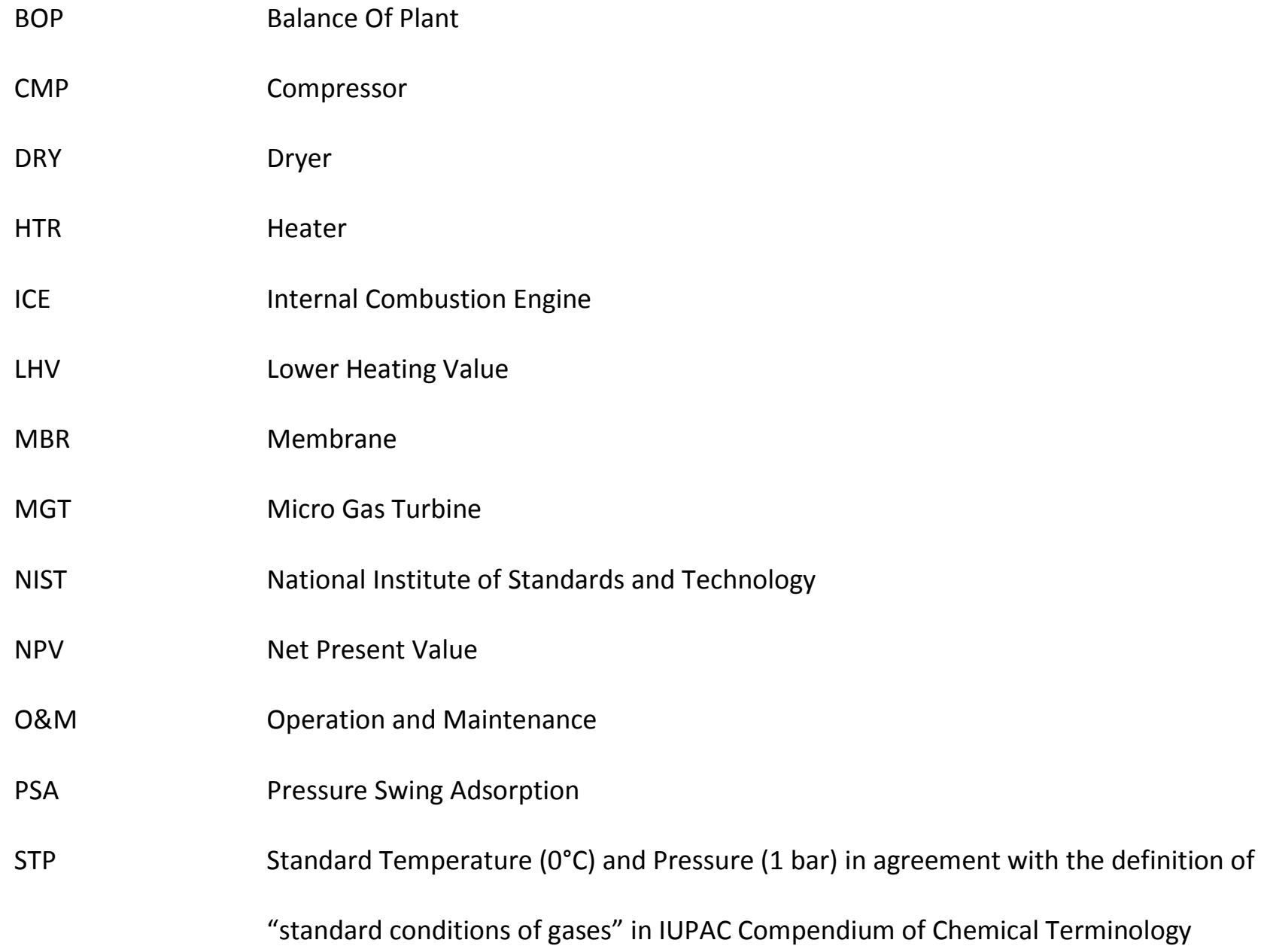




\begin{tabular}{|c|c|}
\hline$\Delta A$ & Small increment of membrane area $\left[\mathrm{m}^{2}\right]$ \\
\hline$\alpha$ & Selectivity \\
\hline$\beta$ & Concentration-dependent parameter $\left[\mathrm{m}^{3} / \mathrm{mol}\right]$ \\
\hline$\delta$ & Membrane thickness $[\mathrm{m}]$ \\
\hline$\varphi$ & Pressure ratio \\
\hline$A$ & Membrane area $\left[\mathrm{m}^{2}\right]$ \\
\hline$C_{H}^{\prime}$ & Saturated concentration of adsorbed gas $\left[\mathrm{mol} / \mathrm{m}^{3}\right]$ \\
\hline$D^{\circ}$ & Effective diffusivity of penetrant gas at infinitely dilute concentration $\left[\mathrm{m}^{2} / \mathrm{s}\right]$ \\
\hline$M$ & Molar flow across the membrane $[\mathrm{mol} / \mathrm{s}]$ \\
\hline$N$ & Permeate molar flow $[\mathrm{mol} / \mathrm{s}]$ \\
\hline$O$ & Residue molar flow [mol/s] \\
\hline$P$ & Permeance $\left[\mathrm{mol} / \mathrm{m}^{2} \mathrm{~s}\right.$ bar $]$ \\
\hline$b$ & Adsorption equilibrium constant $\left[\right.$ bar $\left.^{-1}\right]$ \\
\hline$k_{D}$ & Dissolution coefficient $\left[\mathrm{mol} / \mathrm{m}^{3} \mathrm{bar}\right]$ \\
\hline$p_{h}$ & High pressure or partial pressure [bar] \\
\hline$p_{l}$ & Low pressure or partial pressure [bar] \\
\hline$x_{h}$ & Molar concentration in the high pressure side \\
\hline$x_{l}$ & Molar concentration in the low pressure side \\
\hline
\end{tabular}

496 Subscript and superscript

$\begin{array}{ll}k & k \text {-th incremental area } \\ i & i \text {-th component }\end{array}$

\section{Bibliography}

498 [1] J. B. Holm-Nielsen, T. Al Seadi, P. Oleskowicz-Popiel, The future of anaerobic digestion and biogas utilization, Bioresour. Technol. 100(22) (2009) 5478-5484. doi:10.1016/i.biortech.2008.12.046 
500 [2] E. Ryckebosch, M. Drouillon, H. Vervaeren, Techniques for transformation of biogas to biomethane, Biomass and Bioenergy, 35(5) (2011) 1633-1645, doi:10.1016/i.biombioe.2011.02.033

502 [3] R.W. Baker, K. Lokhandwala, Natural gas processing with membranes: An overview, Ind. Eng. Chem. Res. 47(7) (2008) 2109-2121, doi:10.1021/ie071083w

504 [4] R.W. Baker, Membrane technology and applications, third ed., John Wiley and sons Ltd, 2012.

505 [5] M. Scholz, T. Melin, M. Wessling, Transforming biogas into biomethane using membrane technology, 506 Renew. Sustain. Energy Rev. 17 (2013) 199-212, doi:10.1016/j.rser.2012.08.009

[6] S. Basu, A. Khan, A. Cano-Odena, C. Liu, I. Vankelecom, Membrane-based technologies for biogas separations, Chem. Soc. Rev. 39(2) (2009) 750-768.

[7] M. Harasimowicz, P. Orluk, G. Zakrzewska-Trznadel, A. Chmielewski, Application of polyimide membranes for biogas purification and enrichment, J. of Hazard. Mater. 144(3) (2007) 698-702.

[8] S. Y. Lee, M. D. Donohue, B. S. Minhas, Effect of gas composition and pressure on permeation through cellulose acetate membranes, AIChE Symp. Ser. 261(84) (1988) 93-101.

[9] S. Kanehashi, T. Nakagawa, K. Nagai, X. Duthie, S. Kentish, G. Stevens, Effects of carbon dioxide induced plasticization on the gas transport properties of glassy polyimide membranes, J. of Membr. Sci. 298(1-2) (2007) 147-155.

[10] S. Weller, W. A. Steiner, Engineering aspects of separation of gases. Fractional permeation through membranes, Chem. Eng. Prog. 46(11) (1950) 585-590.

[11] S.A. Stern, W.P. Walawender, Analysis of membrane separation parameters, Sep. Sci. 4(2) (1969) 129-159.

[12] A. L. Kohl, R. B. Nielsen, Membrane Permeation Processes, in: Gas Purification, fifth ed., Gulf Publishing Company, Houston, 1997. 
[13] M.J. Thundyl, W.J. Koros, Mathematical modeling of gas separation permeators - for radial crossflow, countercurrent, and cocurrent hollow fiber membrane modules, J. of Membr. Sci. 125 (1997) 275291.

[14] S. Tessendorf, R. Gani, M. Michelsen, Modeling, simulation and optimization of membrane-based gas separation systems, Chem. Eng. Sci. 54(7) (1999) 943-955.

[15] A. Makaruk, M. Harasek, Numerical algorithm for modelling multicomponent multipermeator systems, J. of Membr. Sci. 344(1-2) (2009) 258-265.

[16] J. Hao, P. Rice, S. Stern, Upgrading low-quality natural gas with $\mathrm{H}_{2} \mathrm{~S}$ and $\mathrm{CO}_{2}$ selective polymer membranes. Part I. Process design and economics of membrane stages without recycle streams, J. of Membr. Sci. 209(1) (2002) 177-206.

[17] J. Hao, P. Rice, S. Stern, Upgrading low-quality natural gas with $\mathrm{H}_{2} \mathrm{~S}$ and $\mathrm{CO}_{2}$ selective polymer membranes. Part II. Process design, economics, and sensitivity study of membrane stages with recycle streams, J. of Membr. Sci. 320 (2008) 108-122.

[18] R. Qi, M. A. Henson, Optimization-based design of spiral-wound membrane systems for $\mathrm{CO}_{2} / \mathrm{CH}_{4}$ separations, Sep. and Purif. Technol. 13 (1998) 209-225.

[19] A. Makaruk, M. Miltner, M. Harasek, Membrane biogas upgrading processes for the production of natural gas substitute, Sep. and Purif. Technol. 74(1) (2010) 83-92.

[20] L. Deng, M.-B. Hägg, Techno-economic evaluation of biogas upgrading process using CO2 facilitated transport membrane, Int. J. of Greenh. Gas Control 4 (2010) 638-646.

\section{[21] http://webbook.nist.gov/chemistry/}

[22] Perry's Chemical engineers' Handbook. Seventh Edition by. D.W. Green, J.O. Maloney. McGraw-Hill Professional, 1997.

[23] C. Walla and W. Schneeberger, The optimal size for biogas plants, Biomass and Bioenergy 32 (2008) 551-557. 


\section{Table captions}

547 Table 1. Assumed values for the cellulose acetate membrane parameters, converted from [8].

548

549 Table 2. Assumed values for the technical and economical parameters (for membrane parameters see Table 1). 550

551

Table 3. Overall performances of the optimized layouts from the energy, exergy and economical perspectives.

552 


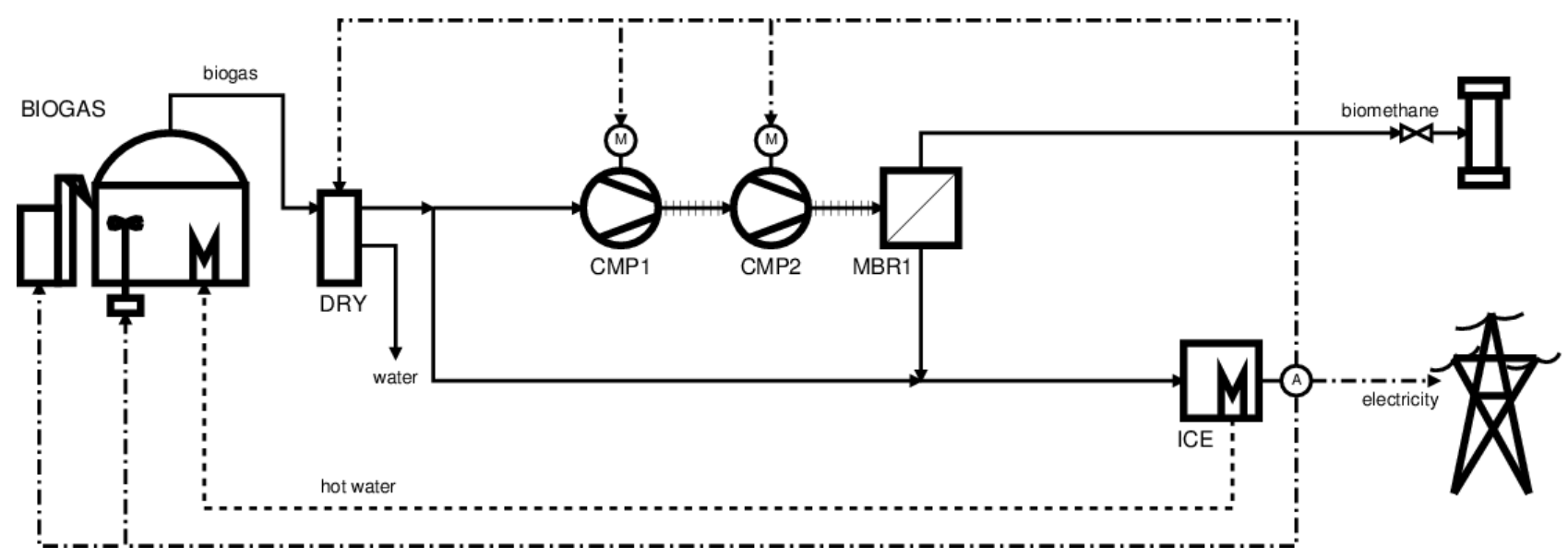

556 Figure 1. Single-stage permeation and internal combustion engine (Layout 1).

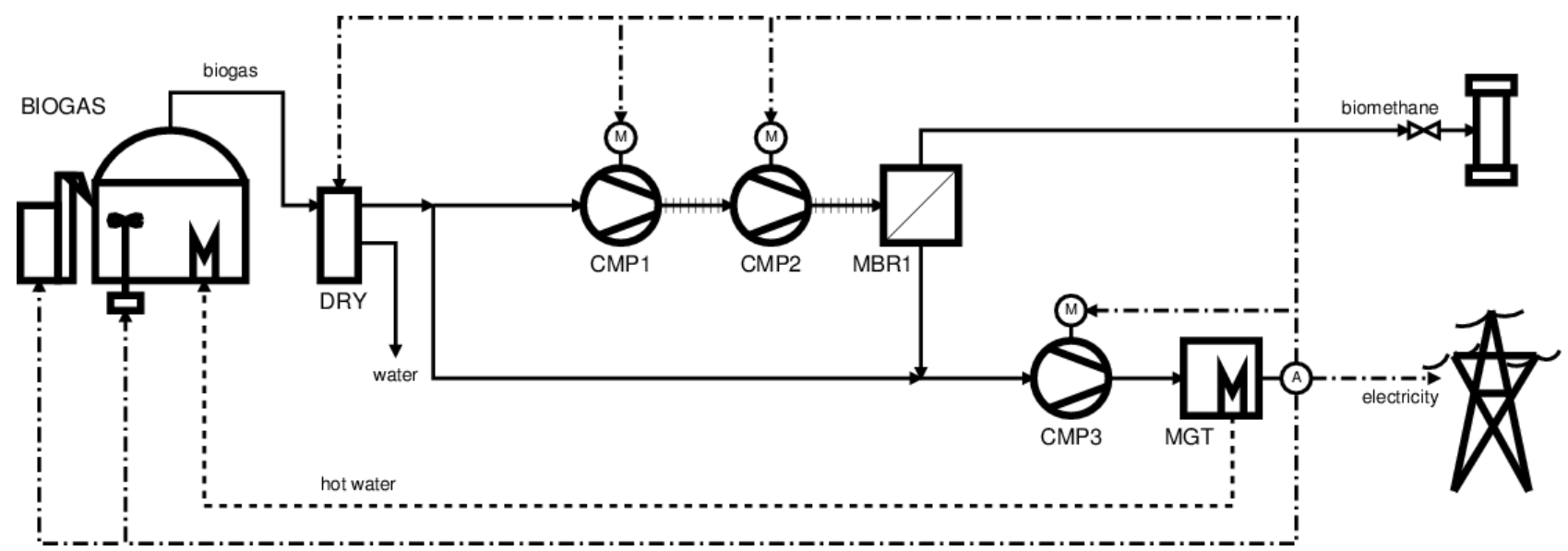

559 Figure 2. Single-stage permeation and micro gas turbine (Layout 2). 


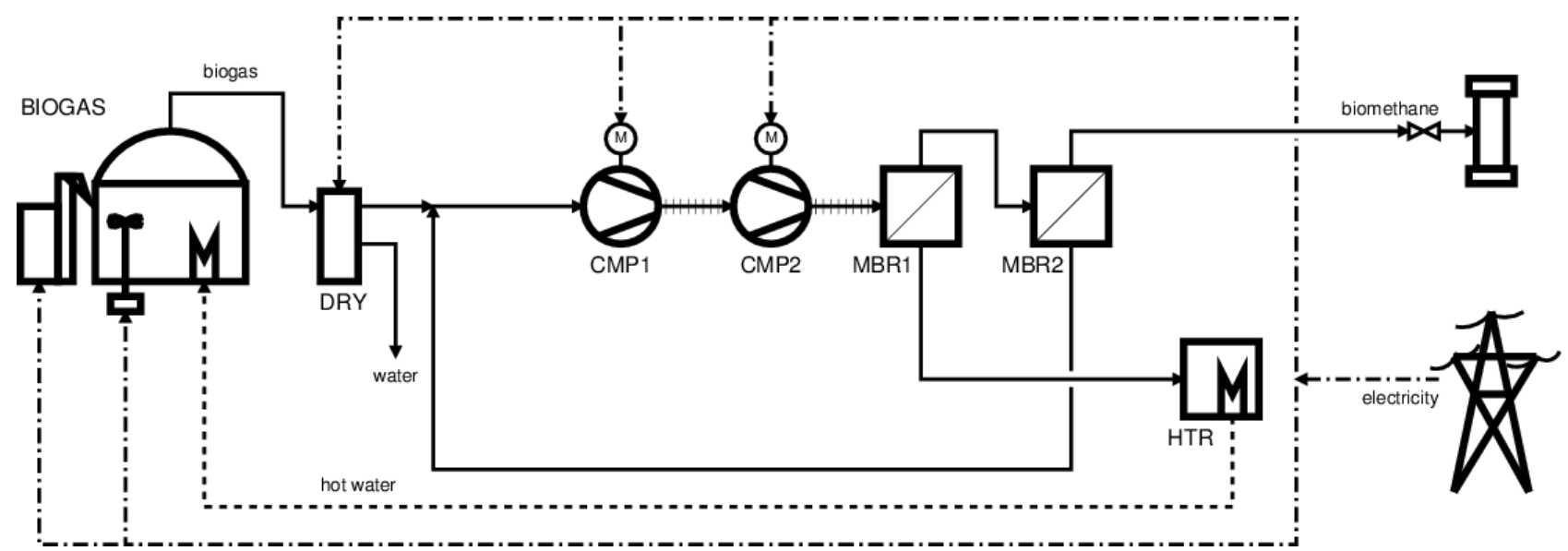

Figure 3. Double-stage permeation with second-stage permeate recycle, single-stage compression and heater

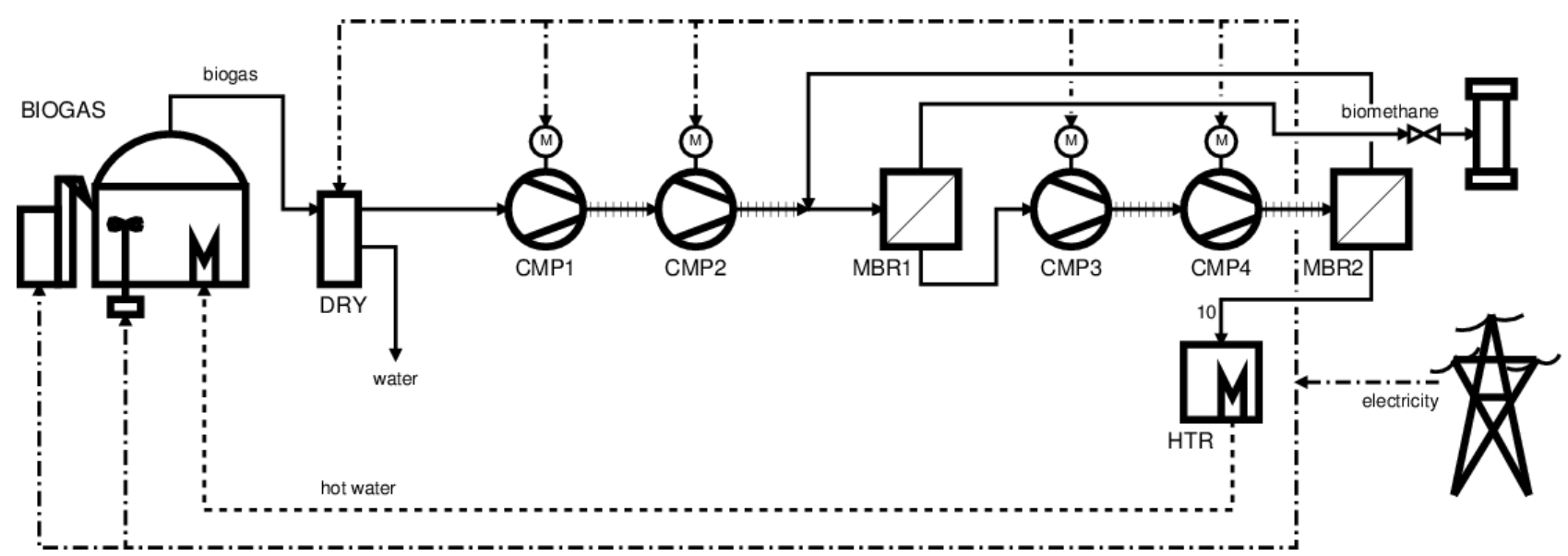

Figure 4. Double-stage permeation with second-stage residue recycle, first-stage permeate recompression and

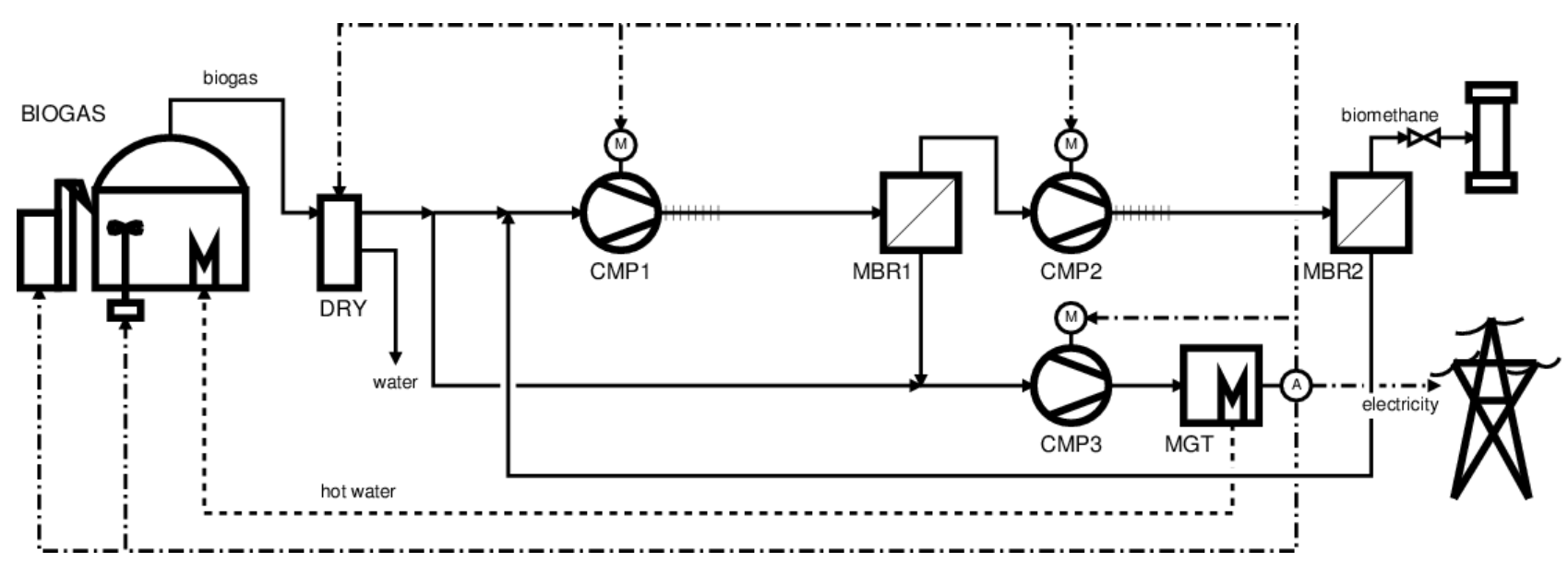

Figure 5. Double-stage permeation with second-stage permeate recycle, two-stage compression and micro gas 


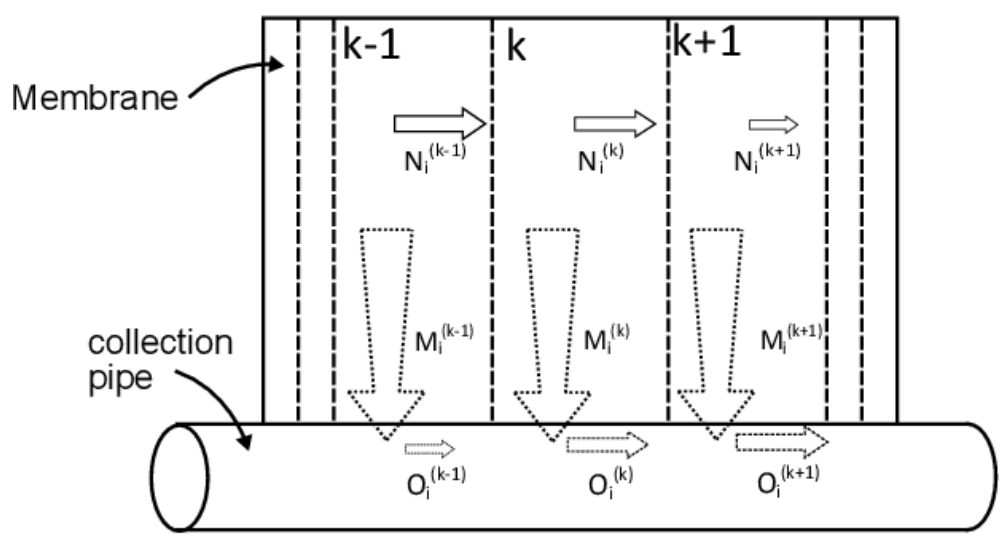

573 Figure 6. Schematic of the numerical solution of the crossflow pattern.

574 


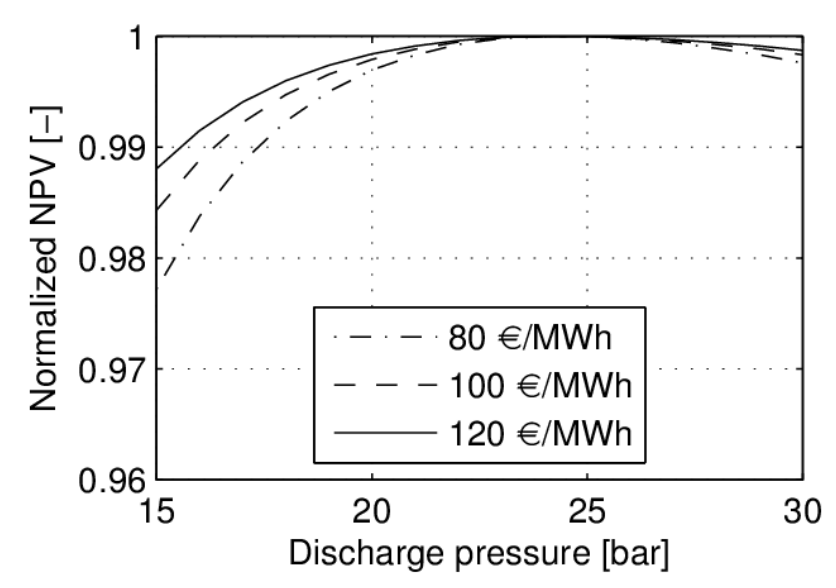

a. Layout 1

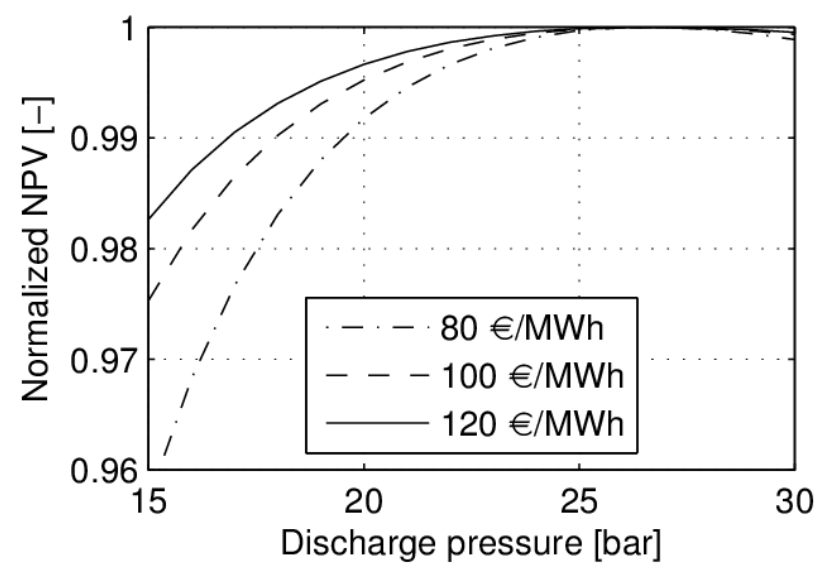

c. Layout 3

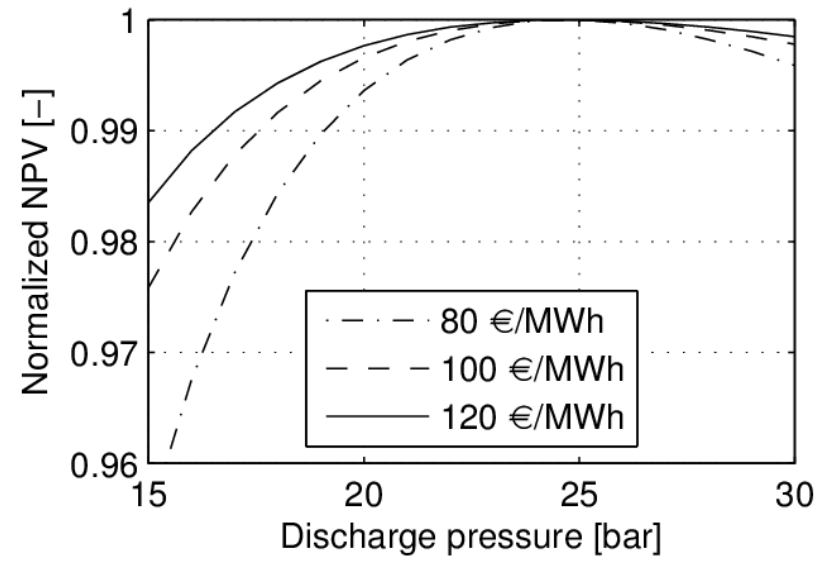

b. Layout 2

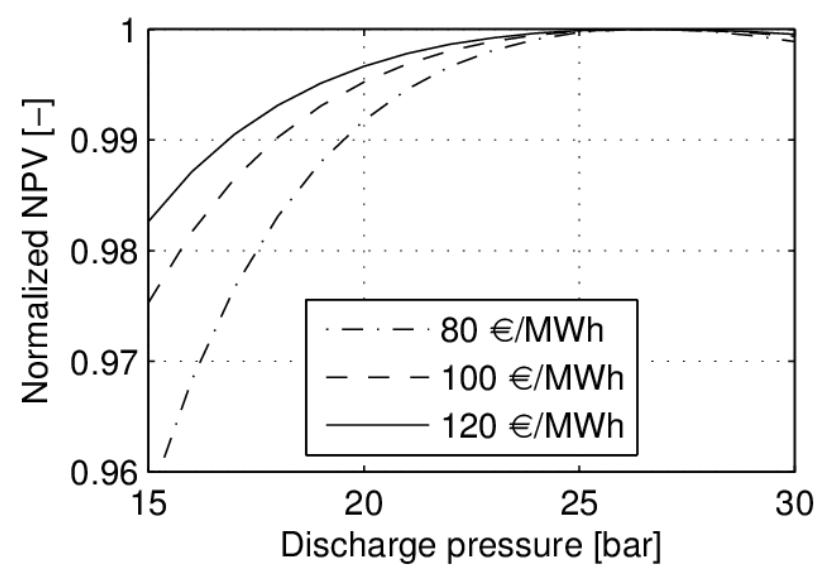

d. Layout 4

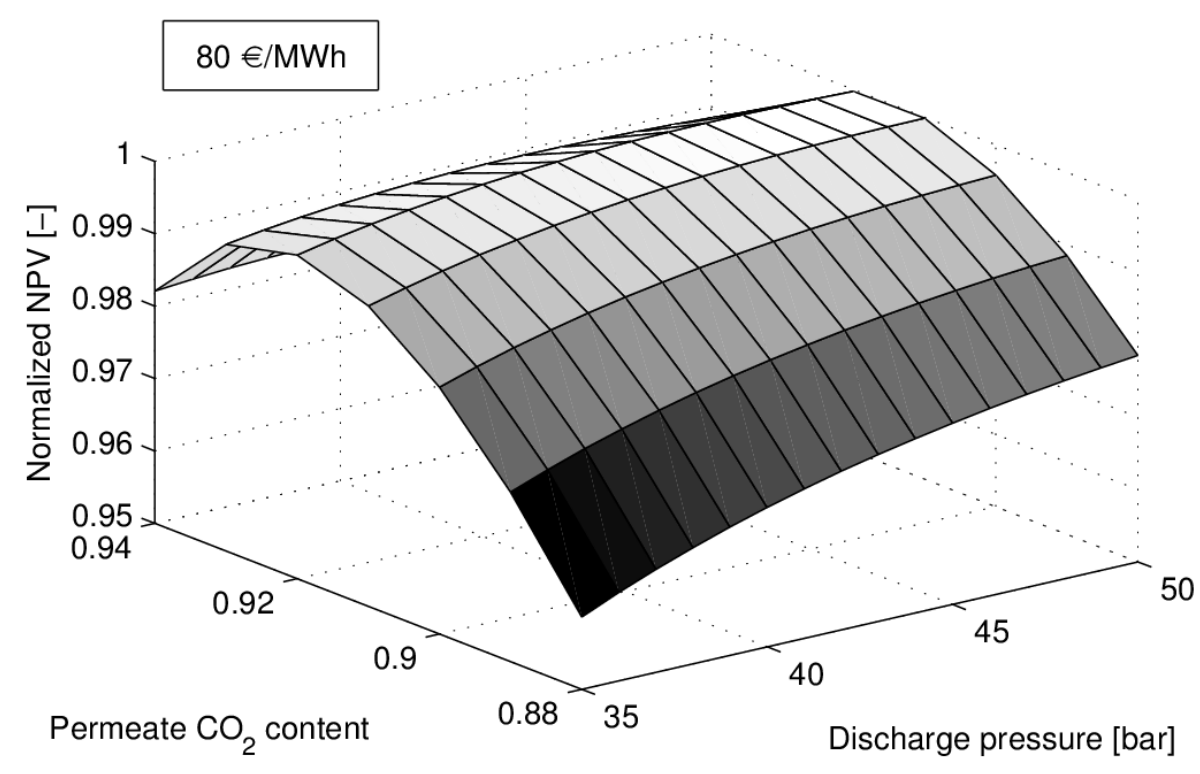

e. Layout 5

Figure 7. Normalized Net Present Value (NPV) [-] as a function of the free parameters for the five layouts: compressor discharge pressure for Layout 1 to 5 , and of permeate $\mathrm{CO}_{2}$ content for just Layout 5 . Curves for Layout 1 to $\mathbf{4}$ are drawn for three biomethane incentive values. Curve for Layout $\mathbf{5}$ is drawn for only one value. Normalization of NPV is executed with respect to the maximum of each curve. 


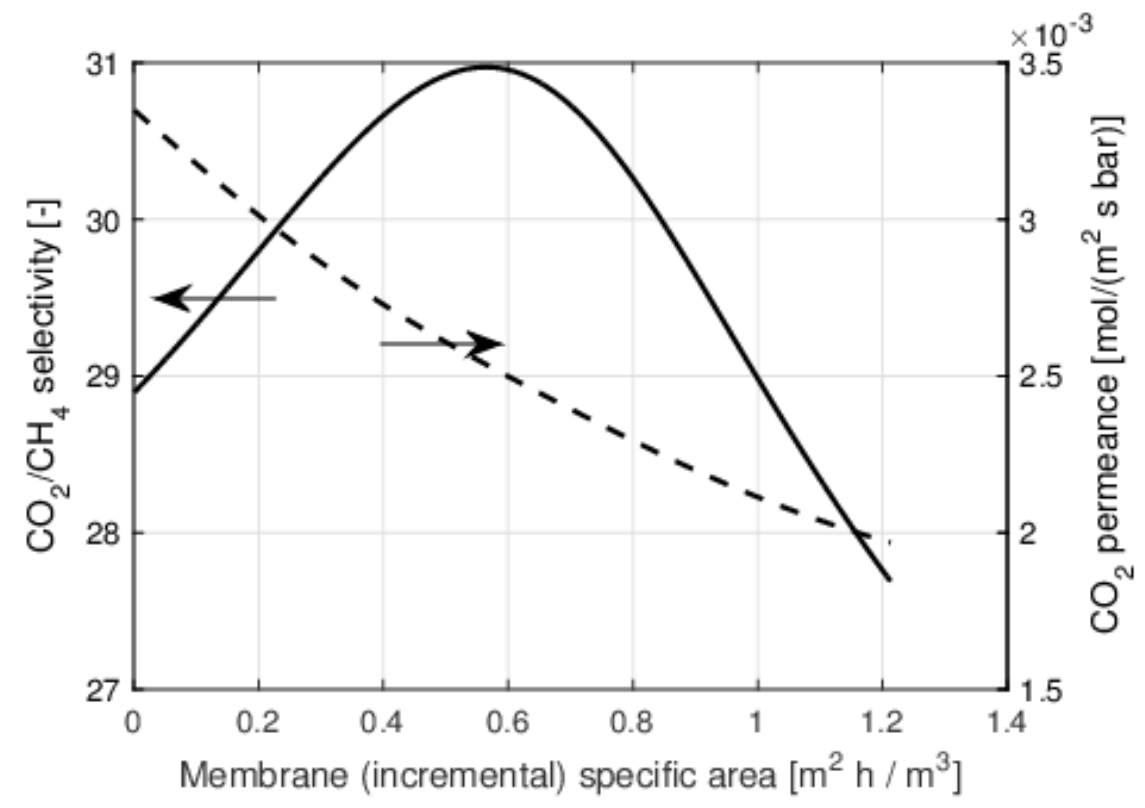

Figure 8. $\mathrm{CO}_{2} / \mathrm{CH}_{4}$ selectivity (solid line) [-] and $\mathrm{CO}_{2}$ permeance (dashed line) $\left[\mathrm{mol} /\left(\mathrm{m}^{2} \mathrm{~s} \mathrm{bar}\right)\right]$ for Layout 1 as a function of the membrane incremental area, which is expressed in specific terms with respect to the produced biomethane (STP conditions) $\left[\mathrm{m}^{2} \mathrm{~h} / \mathrm{m}^{3}\right]$. The total specific area for Layout 1 is $1.23 \mathrm{~m} / \mathrm{h} / \mathrm{m}^{3}$ as reported in Table 3 .

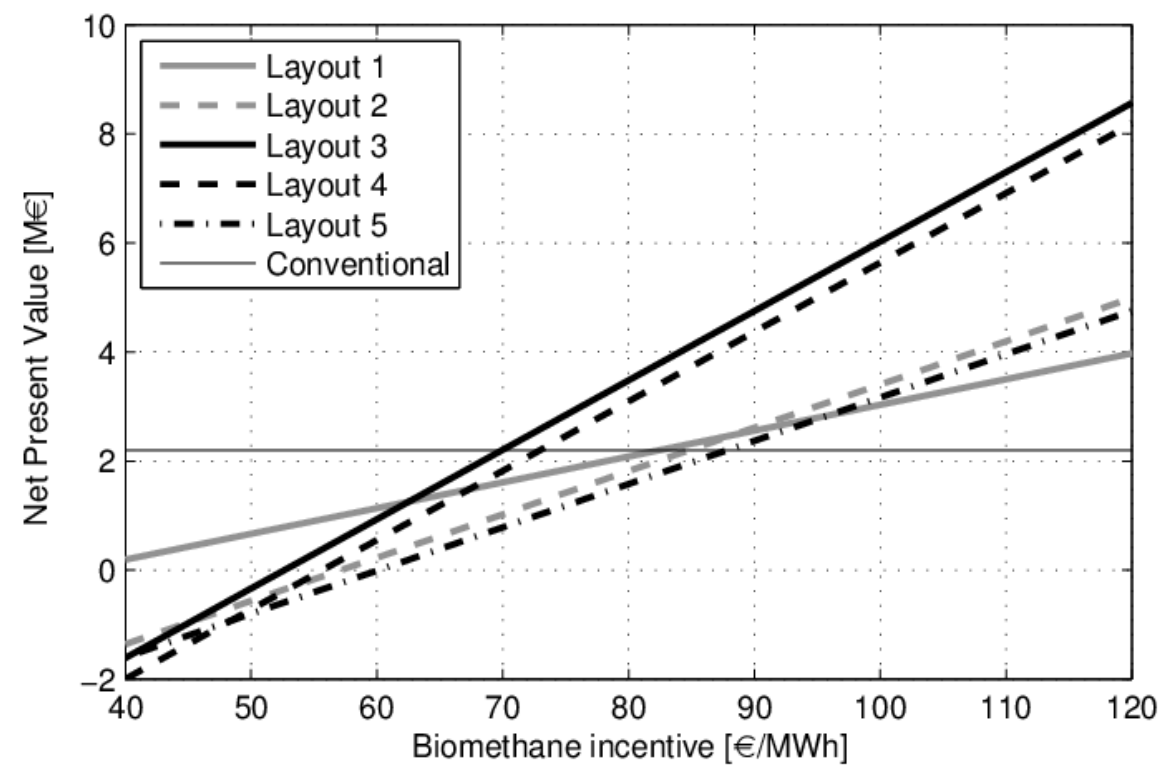

Figure 9. Net Present Value (NPV) [M€] as a function of the biomethane incentive [€/MWh] for the five layouts and 586 for the conventional biogas plant taken in the methodology validation (Sec. 5.1). 


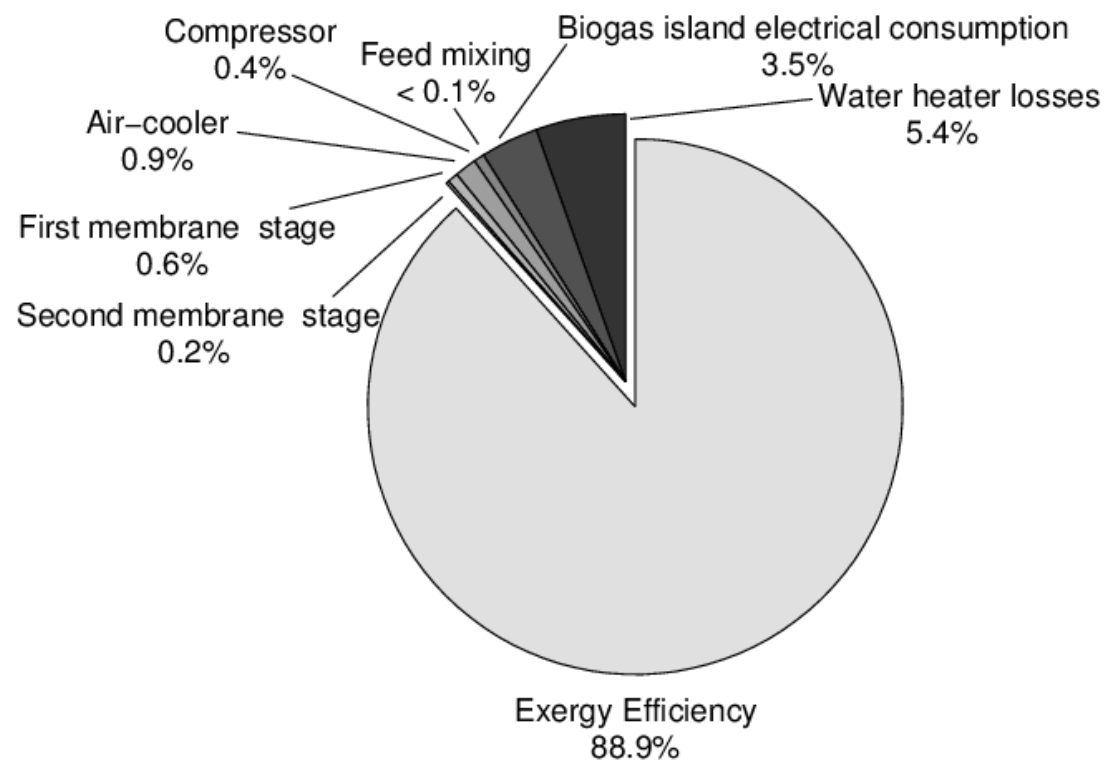

Figure 10. Pie diagram of the exergy losses for the preferred layout (Layout 3).

590

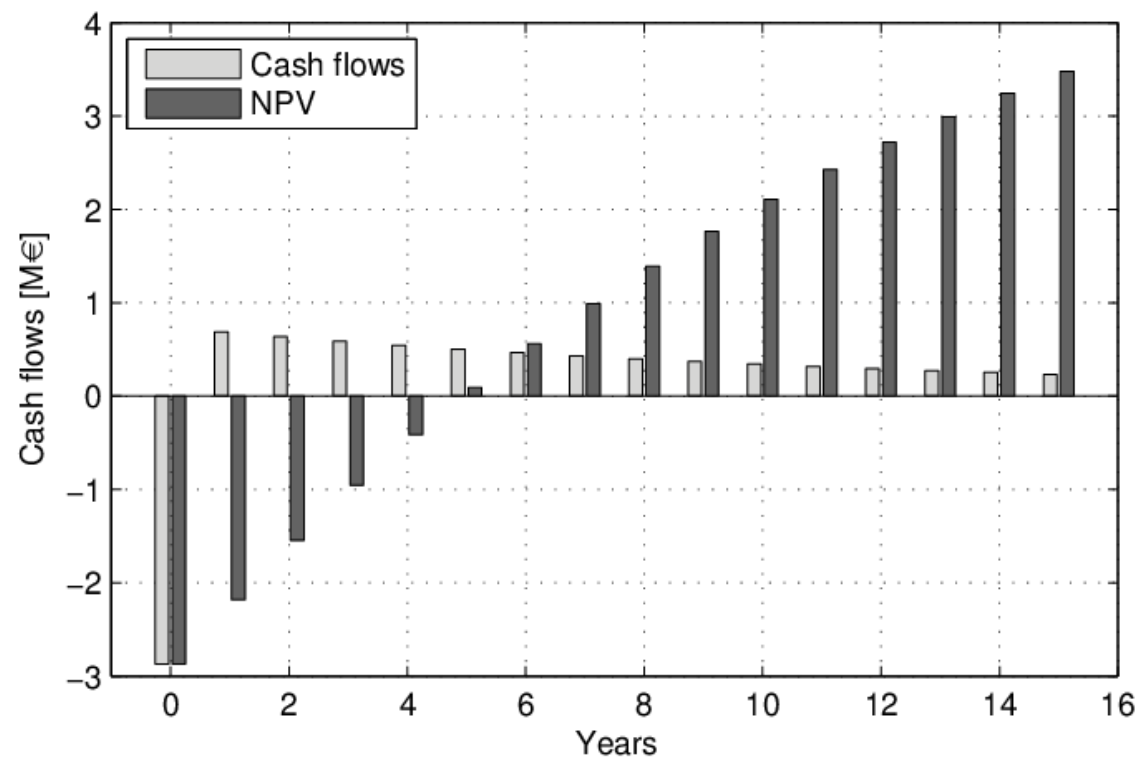

592 Figure 11. Cash flows over the project lifetime for the preferred layout (Layout 3). 
Tables

Table 1. Assumed values for the cellulose acetate membrane parameters, converted from [8].

\begin{tabular}{|c|c|c|c|c|}
\hline Cellulose acetate parameter & Unit & Symbol & Value & \\
\hline & & & $\mathrm{CO}_{2}$ & $\mathrm{CH}_{4}$ \\
\hline $\begin{array}{l}\text { Concentration-dependent } \\
\text { parameter }\end{array}$ & $\mathrm{m}^{3} / \mathrm{mol}$ & $\beta_{i}$ & 0.0018 & 0.0016 \\
\hline $\begin{array}{l}\text { Effective diffusivity of penetrant } \\
\text { gas at infinitely dilute } \\
\text { concentration }\end{array}$ & $\mathrm{m} / \mathrm{s}$ & $D_{i}^{\circ} / \delta$ & \multicolumn{2}{|c|}{$4.420 \mathrm{e}-061.120 \mathrm{e}-06$} \\
\hline $\begin{array}{l}\text { Saturated concentration of } \\
\text { adsorbed gas }\end{array}$ & $\mathrm{mol} / \mathrm{m}^{3}$ & $C_{H}^{\prime}$ & 1629.2 & 1629.2 \\
\hline Adsorption equilibrium constant & bar $^{-1}$ & $b_{i}$ & 0.1900 & 0.0219 \\
\hline Dissolution coefficient & $\mathrm{mol} / \mathrm{m}^{3}$ bar & $k_{D_{i}}$ & 36.3701 & 7.6615 \\
\hline
\end{tabular}


Table 2. Assumed values for the technical and economical parameters (for membrane parameters see Table 1).

\begin{tabular}{|c|c|c|c|c|c|}
\hline Parameter & Unit & Value & Parameter & Unit & Value \\
\hline \multicolumn{3}{|l|}{ Dry biogas to membrane plant } & \multicolumn{3}{|l|}{ Energy and exergy references } \\
\hline Composition & & & Pressure & atm & 1 \\
\hline $\mathrm{CH}_{4}$ & $\%$ & 55 & Temperature & $\mathrm{K}$ & 298.15 \\
\hline $\mathrm{CO}_{2}$ & $\%$ & 45 & $\mathrm{CH}_{4}$ Lower Heating Value (LHV) & $\mathrm{kJ} / \mathrm{mol}$ & 802.3 \\
\hline Pressure & bar & 1 & $\mathrm{CH}_{4}$ chemical exergy & $\mathrm{kJ} / \mathrm{mol}$ & 830.2 \\
\hline Temperature & K & 273.15 & Investment & & \\
\hline Flow rate & $\mathrm{mol} / \mathrm{s}$ & $6.2^{\mathrm{a}}$ & Biogas plant cost & $M €$ & 2.5 \\
\hline \multicolumn{3}{|l|}{ Biomethane to grid } & \multicolumn{2}{|l|}{ Exponential method factor } & 0.7 \\
\hline \multicolumn{3}{|l|}{ Composition } & \multicolumn{3}{|l|}{ Exponential method references } \\
\hline $\mathrm{CH}_{4}$ & $\%$ & 97 & Compressor size & $\mathrm{kW}_{\mathrm{e}}$ & $25^{d}$ \\
\hline $\mathrm{CO}_{2}$ & $\%$ & 3 & Compressor specific cost & $€ / k W$ & $900^{d}$ \\
\hline \multicolumn{3}{|l|}{ Biogas plant } & ICE size & $\mathrm{kW}_{\mathrm{e}}$ & 500 \\
\hline Electrical power requirement & $k W_{e}$ & 100 & ICE specific cost & $€ / \mathrm{kW}_{\mathrm{e}}$ & $900^{\mathrm{e}}$ \\
\hline Thermal power requirement & $\mathrm{kW}_{\text {th }}$ & 200 & MGT size & $\mathrm{kW}_{\mathrm{e}}$ & 65 \\
\hline \multicolumn{3}{|l|}{ Air-cooled compressors } & MGT specific cost & $€ / \mathrm{kW}_{\mathrm{e}}$ & $1800^{\mathrm{e}}$ \\
\hline Isentropic efficiency & $\%$ & 75 & Heater size & $\mathrm{kW}_{\text {th }}$ & 100 \\
\hline Electric efficiency & $\%$ & 95 & Heater specific cost & $€ / \mathrm{kW}_{\text {th }}$ & 60 \\
\hline Fan electric consumption & $\mathrm{kW}_{\mathrm{e}} / \mathrm{kW}_{\text {th }}$ & 0.002 & Membrane specific cost & $€ / \mathrm{m}^{2}$ & 150 \\
\hline \multicolumn{3}{|l|}{ Internal Combustion Engine (ICE) } & Balance Of Plant (BOP) & $\%$ & 200 \\
\hline Net electrical efficiency & $\%$ & $40^{\mathrm{b}}$ & \multicolumn{3}{|l|}{ Yearly cash flows } \\
\hline Max thermal efficiency & $\%$ & 45 & Capacity factor & $\%$ & 85 \\
\hline \multicolumn{3}{|l|}{ Fuel gas } & Biomass cost & k€/year & 350 \\
\hline Min $\mathrm{CH}_{4}$ content & $\%$ & 45 & \multicolumn{3}{|l|}{ Operation \& Maintenance costs } \\
\hline Inlet pressure & bar & 1 & Compressor & $€ / M W h_{e}$ & 5 \\
\hline \multicolumn{3}{|l|}{ Micro Gas Turbine (MGT) } & ICE & $€ / \mathrm{MWh}_{\mathrm{e}}$ & 30 \\
\hline Net electrical efficiency & $\%$ & $33^{c}$ & MGT & $€ / \mathrm{MWh}_{\mathrm{e}}$ & 15 \\
\hline Max thermal efficiency & $\%$ & 50 & Membrane & $€ / \mathrm{m}^{2} /$ year & 30 \\
\hline \multicolumn{3}{|l|}{ Fuel gas } & Other $\mathrm{w} / \mathrm{r} / \mathrm{t}$ total investment & $\%$ & 1 \\
\hline Min $\mathrm{CH}_{4}$ content & $\%$ & 35 & \multicolumn{3}{|l|}{ Electricity } \\
\hline Inlet pressure & bar & 6 & Purchased from grid & $€ / \mathrm{MWh}_{\mathrm{e}}$ & 150 \\
\hline \multicolumn{3}{|l|}{ Heater } & Sold to grid with incentives & $€ / \mathrm{MWh}_{\mathrm{e}}$ & 200 \\
\hline Max thermal efficiency & $\%$ & 90 & Tax rate & $\%$ & 20 \\
\hline \multicolumn{3}{|l|}{ Fuel gas } & \multicolumn{3}{|l|}{ Net Present Value analysis } \\
\hline $\mathrm{MinCH}_{4}$ content & $\%$ & 10 & Project lifetime & years & 15 \\
\hline Inlet pressure & bar & 1 & Weighted average cost of capital & $\%$ & 8 \\
\hline
\end{tabular}

a equivalent to $500 \mathrm{~m}^{3} / \mathrm{h} \mathrm{STP}$

${ }^{\mathrm{b}}$ typical for an internal combustion engine rated at an electrical power from 500 to $800 \mathrm{kWe}$

${ }^{c}$ typical for a micro gas turbine rated at an electrical power of $200 \mathrm{~kW}$ excluding the fuel compressor power requirement

d includes the cost for the corresponding air cooler

e includes the exhausts heat exchanger 
Table 3. Overall performances of the optimized layouts from the energy, exergy and economical perspectives.

\begin{tabular}{|c|c|c|c|c|c|c|}
\hline \multirow[t]{2}{*}{ Optimal parameter } & \multirow[t]{2}{*}{ Unit } & \multicolumn{5}{|c|}{ Layouts } \\
\hline & & $\overline{1}$ & 2 & 3 & 4 & 5 \\
\hline Compressor discharge pressure $^{a}$ & Bar & 24 & 24 & 26 & $24 / 24$ & $6.8 / 46$ \\
\hline Permeate $\mathrm{CO}_{2}$ content & $\%$ & NA & NA & NA & NA & 0.92 \\
\hline Membrane area (MBR1) & $m^{2}$ & 118.2 & 198.3 & 121.0 & 313.0 & 340.7 \\
\hline Membrane area (MBR2) & $\mathrm{m}^{2}$ & NA & NA & 165.8 & 54.2 & 49.2 \\
\hline Compressor size (CMP1) & $k W_{e}$ & 15.0 & 25.1 & 44.2 & 37.8 & 38.3 \\
\hline Compressor size (CMP2) & $k W_{e}$ & 16.3 & 27.4 & 48.3 & 41.2 & 23.5 \\
\hline Compressor size (CMP3) & $\mathrm{kWe}$ & NA & 32.1 & NA & 21.6 & 32.1 \\
\hline Compressor size (CMP4) & $k W_{e}$ & NA & NA & NA & 21.6 & NA \\
\hline Prime mover size (ICE or MGT) & $k W_{e}$ & 723.2 & 389.2 & NA & NA & 389.2 \\
\hline Water heater size (HTR) & $\mathrm{kW}_{\mathrm{th}}$ & NA & NA & 216.1 & 216.1 & NA \\
\hline Biomethane flow rate & kWLHV & 927.9 & 1556 & 2496 & 2496 & 1556 \\
\hline Methane recovery & $\%$ & 33.9 & 56.9 & 91.2 & 91.2 & 56.9 \\
\hline Electricity ${ }^{b}$ & $k W_{e}$ & 591.3 & 203.5 & -194.4 & -224.4 & 193.9 \\
\hline Specific area & $\mathrm{m}^{2} \mathrm{~h} / \mathrm{m}^{3}$ (STP) & 1.23 & 1.23 & 1.11 & 1.42 & 2.42 \\
\hline Specific separation energy ${ }^{c}$ & $\mathrm{kWh} / \mathrm{m}^{3}$ (STP) & 0.33 & 0.33 & 0.36 & 0.47 & 0.38 \\
\hline Exergy efficiency & $\%$ & 57.7 & 67.1 & 88.9 & 87.9 & 67.0 \\
\hline Total investment & $M €$ & 4.40 & 4.04 & 2.87 & 3.00 & 4.14 \\
\hline Yearly cash flow ${ }^{d}$ & $k € /$ year & 757 & 684 & 741 & 712 & 668 \\
\hline Payback time $^{d}$ & Years & 9 & 9 & 5 & 6 & 9 \\
\hline Net Present Value ${ }^{d}$ & $M €$ & 2.08 & 1.81 & 3.48 & 3.09 & 1.58 \\
\hline
\end{tabular}

a the compressor for the micro gas turbine in Layout 2 and 5 has a discharge pressure defined in Table 2

${ }^{b}$ positive if sold to the grid, negative if purchased from the grid

${ }^{c}$ the specific separation energy includes only the work for the separation compressors

${ }^{d}$ computed with a biomethane incentive of $80 € / M W h_{L H V}$ 